\title{
EDUCAÇÃO FÍSICA ESCOLAR E INCLUSÁOO: DESAFIOS PARA UMA PRÁTICA CONCRETA
}

\author{
RéGis Henrique dos Reis Silva ${ }^{1}$ \\ SÔNIA BERTONI SOUSA ${ }^{2}$ \\ Maria Helena Candelori Vidal ${ }^{3}$
}

\begin{abstract}
Resumo
Este artigo tem como objetivo discutir qual é o papel da Educação Física Escolar, diante do paradigma da inclusão. Para isto fez-se necessário abordar também as seguintes questôes: Quais os princípios que orientam a Educação Especial (EE)? Em relação à Educação Inclusiva, quais fatos e correntes de pensamento vêm orientando o seu desenvolvimento? Quais as orientaçôes das políticas educacionais brasileiras relacionadas à EE, no cenário da integração e inclusão? O que têm demonstrado os dados estatísticos brasileiros, quanto à inclusão das Pessoas com Necessidades Educacionais Especiais (PNEE) na rede de ensino público e/ou privado? E quais os caminhos percorridos pela área da Educação Física diante das PNEE?
\end{abstract}

PALAVRAS-ChaVE: educação física, educação especial, inclusão escolar.

School Physical Education and inclusion: challenges for one concrete practical

\section{AbSTRACT}

This paper aims at discussing the School Physical Education's role in face of Inclusion paradigm. To reach our aim, we had to refer to the following questions: what are the principles which orientate Special Education (SE); in relation to Inclusive Education, what are the facts and thoughts which orientate its development; what are the orientations of Brazilian Educational Politics related to Special Education, in the scenery of integration and inclusion; what have shown the Brazilian statistical dates concerning to the inclusion of People with Educational Special Needs in private or public schools; and what are the traveled ways by Physical Education in face of People with Educational Special Needs?

KeY WORDS: physical education, special education, school inclusion.

Professor de Educação Física do Cepae/UFG. E-mail: regishsilva@universia.com.br.

2 Professora de Educação Física da Rede Municipal de Uberlândia/MG-NADH/PMU, cedida ao NIAFS/FAEFI/UFU e professora da UNIPAM. E-mail: bertoni@ras.ufu.br.

3 Professora de Educação Física da Rede Municipal de Uberlândia/MG, cedida ao NIAFS/FAEFI/UFU e professora da UNIPAC. E-mail: mhvidal@faefi.ufu.br. 
146 RevistaSoltaa Voz, v. 17, n. 2

\section{INTRODUÇÃO}

Este trabalho é resultado de estudos e palestras realizadas por um grupo de professores de Educação Física, que, desde dezembro de 2002, tem se reunido para discutir questôes referentes à inclusão escolar das Pessoas com Necessidades Educacionais Especiais (PNEE), mais precisamente, à inclusão desse alunado nas aulas de Educação Física.

$\mathrm{Na}$ área educacional vem-se utilizando diferentes denominações, como Pessoas Deficientes, Pessoas Portadoras de Deficiências e Pessoas Portadoras de Necessidades Especiais, porém, a que tem prevalecido é a denominação "Pessoas com Necessidades Educacionais Especiais", por isso, utilizaremos essa denominação neste artigo. Entendemos que essa expressão parte de uma concepção de educação que não se restringe à instituição escolar ou à escolarização, mas refere-se à pessoa humana em suas relações na e com a sociedade.

A inclusão, para autores como Stainback e Stainback (apud Doré et al, 1998), Sassaki (1997 e 1998), Mantoan (1997 e 1998), Mittler (1999) e Carmo (2001), trata-se de um novo paradigma e, conseqüentemente, traz de maneira geral reflexões sobre a Educação e Educação Física Escolar.

Conforme Mendes (2002), a política de inclusão surgiu nos Estados Unidos da América, a partir da segunda metade dos anos 70, visando inserir não só as Pessoas com Deficiência (PD), mas todas as PNEE "excluídas" da escola e sociedade. No Brasil, essa perspectiva tomou impulso nos anos 90, e provavelmente fará parte das discussões educacionais nas primeiras décadas do século XXI.

Diante disso, levantamos o seguinte questionamento: Qual é o papel da Educação Física Escolar, diante do paradigma da inclusão?

Para responder a esta indagação discutimos também as seguintes questôes: quais os princípios que orientam a Educação Especial (EE)? Em relação à Educação Inclusiva, quais fatos e correntes de pensamento vêm orientando o seu desenvolvimento? Quais as orientaçôes das políticas educacionais brasileiras relacionadas à EE, no cenário da integração e inclusão? O que têm demonstrado os dados estatísticos brasileiros, quanto à inclusão das PNEE na rede de ensino público e/ou privado? E quais os caminhos percorridos pela área da Educação Física diante das PNEE? 


\section{PRINCÍPIOS QUE ORIENTAM A EDUCAÇĀO ESPECIAL}

Em relação aos princípios que orientam a Educação Especial, podemos dizer que, historicamente, apresentam três momentos distintos: o da normalização, o da integração e o da inclusão.

O princípio da normalização iniciou-se na Dinamarca, em 1950, tendo sido contemplado na legislação desse país em 1959. Baseia-se na idéia de que indivíduos com deficiência têm direito de usufruir condiçôes de vida os mais normais possíveis, os mais similares às condiçôes das outras pessoas. Não se trata de normalizar as pessoas, mas sim o contexto em que se desenvolvem. Segundo Carmo (1998), esse princípio dissemina a idéia da possibilidade de igualar o desigual.

Num segundo momento, em 1970, surgiu uma outra fase, quando se passou a valorizar o princípio da integração. A terceira fase apareceu em 1975 , demarcada pelo princípio da inclusão, que visa integrar não só as pessoas com deficiência, mas todos os alunos anteriormente excluídos, das escolas regulares.

Os princípios da integração e inclusão têm sido, atualmente, os eixos das discussões em congressos, seminários, eventos e publicações na área da Educação/Educação Especial, por estudiosos e pesquisadores, tanto em nível nacional quanto internacional. Assim, procuramos abordar mais especificamente sobre a integração e inclusão.

Em relação aos termos integração e inclusão, constatamos que apresentam significados semelhantes no dicionário da língua portuguesa. A integração é definida como uma ação ou política que visa integrar em um grupo as minorias raciais, religiosas, sociais, e o ato de integrar implica juntar-se, tornando-se parte integrante, reunir-se, incorporar-se. Incluir figura como inserir e introduzir, e inclusão, o ato ou efeito de incluir. Assim, as definições dos dois termos contidas no dicionário não apresentam diferenças significativas, pois ambas remetem à idéia de inserção e junção.

Contudo, verificamos, a partir da revisão de literatura, que, apesar de não existir uma única definição a respeito do que vem a ser integração e inclusão, alguns aspectos são elucidativos de seus significados mais atuais, quais sejam: 1) os princípios da inclusão não são específicos da Educação Especial, ao passo que os da integração os são; 2) o princípio da integração apresenta como pressuposto ideológico que todos são iguais e por isso podem estar juntos. Na inclusão, o princípio básico é que todos são diferentes 


\section{RevistaSoltaa Voz, v. 17, n. 2}

e, por isso, devem conviver com essas diferenças; e 3) no que diz respeito, à perspectiva da escola e da educação, constatamos que, para a integração, o que se pretende é inserir o aluno no sistema de ensino, o que pode ocorrer em classes regulares, com apoio especial (por exemplo: salas de recurso ou de apoio, professor itinerante e etc.). A proposta da inclusão não se restringe às pessoas com deficiência. A perspectiva é que todos tenham garantido os direitos de acesso e permanência à educação escolar.

No paradigma que determina a política de inclusão escolar, a Educação Especial terá outro significado, deixará de ser especial e de atender um segmento da população, para ser uma educação que promova um ensino de especial qualidade a todos.

O princípio da integração, no nosso entendimento, não conseguiu sustentar a inserção do aluno com deficiência na escola e nos diferentes espaços sociais de forma concreta, respeitando e aceitando, objetivamente, as diferenças e a diversidade humana. Não conseguiu, portanto, efetivar um ensino de qualidade à pessoa com deficiência e suas práticas determinaram um falso movimento social. $\mathrm{O}$ mesmo poderá ocorrer com a inclusão se as ações concretas nessa direção não forem implantadas com bases sólidas, com mudanças estruturais na organização da escola, buscando uma nova visão de homem, mundo e sociedade.

Portanto, tanto os princípios que orientam a integração quanto os que orientam a inclusão são limitados. O primeiro, por advogar a igualdade entre os homens, o que a nosso ver não se sustenta nem teoricamente, nem na realidade social concreta. O segundo, por sustentar-se no discurso da diferença entre os homens e advogar, abstratamente, a igualdade de direitos e oportunidades.

Vale ressaltar que, historicamente, alguns fatos marcaram o desenvolvimento da educação inclusiva, como a Declaração Mundial dos Direitos Humanos, preconizada, legalmente, há mais de 60 anos. Em março de 1990, a Conferência Mundial de Educação para Todos, realizada em Joimtiem, na Tailândia, veio reforçar esses direitos, cujo objetivo foi refletir sobre e enfrentar o desafio da exclusão escolar de milhões de alunos, entre eles as pessoas com deficiência. E, ainda mais recente, destacamos a Declaração de Salamanca (Brasil, 1994), realizada na Espanha em 1994, resultado de uma reunião de vários países, inspirada nos princípios de integração e no reconhecimento da necessidade de ação para conseguir "escola para todos", na qual se buscou um consenso mundial sobre os futuros rumos 
dos serviços educativos especiais: combater a exclusão escolar e reduzir a taxa de analfabetismo.

\section{EdUCAÇÃO INCLUSIVA: FATOS E CORRENTES DE PENSAMENTOS}

Em relação aos fatos e correntes de pensamento que vêm orientando o desenvolvimento da Educação Inclusiva, Carmo (2001) assinala a existência de duas correntes: a dos legalistas, que respaldam a inclusão em bases legais do "direito de todos" e dever do Estado, e a dos adaptadores, que visam adaptar a escola em seu caráter aparente, podendo ser chamados de "adaptadores" sociais ou restauradores escolares e da educação.

Concordamos com Carmo (2001) que tanto uma corrente como a outra não apresenta consistência em seu discurso para sustentar a inclusão. Os legalistas acabam concretizando uma ação desarticulada, sem consistência e compromisso com a realidade objetiva das escolas brasileiras, proporcionando segregação, comprometimento da auto-estima das $\mathrm{PD}$, que, incapazes de responder às exigências da escola regular, acabam mais uma vez excluídos de seu interior.

Carmo (2001) ainda explica que os restauradores acreditam que para ocorrer a inclusão o mais importante é reformar as escolas, de forma superficial ou aparente, promovendo mudanças, tais como: adaptações arquitetônicas, adequação dos conteúdos curriculares, preparação dos professores e outras alteraçōes de caráter metodológico. Desconsideram, portanto, a incompatibilidade histórica que sempre existiu entre os projetos político-pedagógicos das escolas especiais e os das regulares, propondo alteraçōes superficiais na organização do espaço escolar, deixando de discutir elementos importantes para o processo de inclusão.

Concordamos com os autores que advogam uma nova forma de organização escolar como meio de concretizar uma escola para todos, o que implica, necessariamente, uma mudança de paradigma. Outros autores também defendem a necessidade de uma nova forma de organização escolar: Saint-Laurent (1997), Sassaki (1997 e 1998); Mittler (1999), Stainback e Stainback (1999), Dalbério (2000) e Carmo (2001).

De forma sintética, podemos afirmar que os autores que sustentam uma nova organização escolar o fazem a partir de dois princípios básicos, a saber: 1) todos os homens são diferentes, possuem uma identidade (singularidade), que os distingue dos demais, porém apresentam algo 
150 RevistaSoltaa Voz, v. 17, n. 2

que também os unem (universalidade). Assim sendo, o processo educativo na escola, se constituirá nessa tensão dialética sem primazia de um sobre outro; e 2) a construção do conhecimento se dá nas relaçōes históricas e sociais. Nesse sentido, as escolas devem redimensionar o tempo e o espaço escolar, rompendo com a fragmentação do conhecimento e considerando o "estatuto histórico" dos alunos.

\section{Políticas educacionais bRASILEIRAS RELACIONADAS À EE}

O que poderíamos destacar no contexto brasileiro, no caso das políticas educacionais integracionistas, seria a omissão do poder público no que diz respeito ao equacionamento da EE no sistema educacional do País e a inexistência da rede de serviços capaz de atender ao alunado brasileiro com NEE.

Isto nos permite afirmar que, a integração escolar no Brasil não saiu da retórica, pois uma grande parte de brasileiros não teve acesso ao sistema educacional. O que de certa forma acabou nos beneficiando, já que, pelo fato de o país ter oferecido um pequeno número de serviços especiais, acabou minimizando os mecanismos de exclusão, assumido pela EE na parceria com a ER, no cenário da integração.

Já em relação à inclusão, estamos iniciando um processo e neste momento a Constituição Federal (Brasil, 1988); a Lei de Diretrizes e Bases da Educação Nacional n. 9394/96 (Brasil, 1996); o Estatuto da Criança e do Adolescente; o Plano Nacional de Educação (Brasil, 2004); os Parâmetros Curriculares Nacionais (Brasil, 1999) e a Proposta da Sociedade Brasileira (PSB) estabelecem que a educação é direito de todos e que as pessoas com NEE devem ter atendimento educacional, preferencialmente, na rede regular de ensino, mas garante atendimento educacional especializado às PD.

Isto quer dizer que a legislação não determina que a matrícula da PNEE tenha que ser obrigatoriamente na classe comum da escola regular. Isto permite que o dispositivo legal seja cumprido caso a inserção ocorra via classe comum associada à classe de recurso ou professor itinerante, ou ainda classe especial.

Para Mendes (s.d.), a Resolução n. 95, de 21 de novembro de 2000, da Secretaria de Educação do Estado de São Paulo, apresenta um pequeno avanço, pois estabelece que a EE para atendimento de educandos com NEE deve ser realizada, preferencialmente, na rede regular de ensino, em 
classes comuns com apoio de serviços especializados organizados na própria escola ou em centros de apoio regionais.

Ainda, de acordo com Mendes, apesar de a Resolução manter a idéia do continuum de serviços,

ela avança no sentido de adotar uma diretriz política que pode se tornar no diferencial para viabilizar a mudança de paradigmas, que seria a colocação preferencial não apenas na escola regular, mas mais especificamente na classe comum das escolas regulares (Mendes, s.d, p. 22/grifos nossos).

É importante observar que a resolução não determina que os apoios devam ser oferecidos necessariamente, mas ainda preferencialmente, na rede regular de ensino, em classes comuns, o que acaba permitindo que a inserção ocorra quase que exclusivamente via classe de recurso, o que pode continuar mantendo a situação atual e dificultar a junção necessária entre ER e EE.

Outros pesquisadores no Brasil vêm dedicando seus estudos às políticas educacionais brasileiras relacionadas à $\mathrm{EE}$, dentre eles, podemos destacar os trabalhos de Ferreira (1998) e Kassar (1998).

Ferreira (1998) analisou os dispositivos referentes à EE na Lei de Diretrizes e Bases da Educação Nacional (LDBEN) n. 9394/96, que apontam para uma ação mais ligada aos sistemas e programas de ensino regular. $\mathrm{O}$ autor verificou que há uma perspectiva positiva na lei, quanto à questão da EE subsidiar a ER pública, preservando a idéia do continuum, no que diz respeito a este, ele observa: "Se a legislação se fixar de modo dominante nas características pessoais e deixar em segundo plano as condições do sistema de ensino, pode ser dificultado o surgimento de programas menos restritivos". E conclui, dizendo, sobre a necessidade da EE e a ER estabelecerem parcerias na educação da PNEE, e que as garantias legais à essa população contrapõe-se à política neoliberal (Estado Mínimo).

Segundo Frigotto (1991), o modelo de desenvolvimento neoliberal caracteriza-se entre outras coisas pela desobrigação do estado com as políticas sociais (educação, saúde, previdência e outras).

Já o estudo de Kassar (1998) discute sobre algumas implicações do pensamento neoliberal na $\mathrm{EE}$, abordando aspectos relativos à regulamentação dos serviços públicos e privados de atendimento nesse setor. A autora verificou que a concomitância desses serviços na educação brasileira, mais precisa- 


\section{Revista Soltaa Voz, v. 17, n. 2}

mente na EE, tem gerado um discurso ambíguo na legislação do País, pois "ao mesmo tempo em que propõe o atendimento 'integrado' na rede regular de ensino, delega às instituiçōes sob administração particular a responsabilidade de parte do atendimento, através da 'garantia' de apoio financeiro".

Kassar (1998) ainda observa que os debates de políticas públicas no Brasil são antagônicos, prevalecendo, assim, as estratégias de conciliação. A autora conclui, afirmando que o discurso hegemônico na EE é sustentado pelo pensamento neoliberal, que preconiza a organização autônoma da população na formação de associaçôes privadas, o que colabora para o afastamento gradativo do Estado quanto a sua responsabilidade sobre várias questões sociais (educação, saúde, previdência e outras).

Ao analisarmos alguns textos que discutem políticas educacionais brasileiras relacionadas à EE, por exemplo, Aranha (2000), Bueno (2001), Ferreira (1998), Kassar (1998), Mendes (2000) e outros, constatamos: 1) o descaso das políticas públicas brasileiras com relação à área de EE; 2) que a EE tem pouca expressão política no contexto da ER; 3) que a EE vem crescendo nos últimos 25 anos; e 4) que as discussōes políticas no Brasil são realizadas num cenário antagônico, prevalecendo, assim, as estratégias de conciliação na elaboração das leis.

Desta forma, as políticas educacionais no País, relacionadas à EE, são muitas vezes indicativas e não prescritivas, pois ao mesmo tempo em que elas devem atender aos interesses neoliberais, também precisam atender aos interesses dos grupos sociais minoritários que defendem seus direitos como cidadãos.

Infelizmente, pelo fato destas leis serem indicativas, elas permitem que a situação do alunado com NEE permaneça praticamente inalterada, isto é, passam-se as décadas, mudam-se os nomes (normalização, integração e/ou inclusão) e a grande maioria das crianças com NEE, cerca de $90 \%$, continua excluída da escola e desta forma, impedida de ter acesso ao conhecimento produzido pela humanidade e das benesses advindas deste. Com base nos dados publicados na reportagem do jornal Folha de São Paulo, do dia 27 de março de 2001, cuja fonte fora o Ministério da Educação e Cultura (MEC), estima-se que no País exista aproximadamente seis milhôes de crianças e jovens com NEE.

Com o intuito de explicitarmos a função perversa assumida pelo caráter indicativo das leis brasileiras, acerca da inclusão das PNEE, apresentamos no quadro, a seguir, os dados estatísticos da inclusão escolar no Brasil. 
RevistaSoltaa Voz, v. 17, n. 2153

QUADRO 01: Dados estatísticos brasileiros, relativos à inclusão das PNEE na rede de ensino público e/ou privado.

\begin{tabular}{|c|c|c|c|c|c|c|c|c|}
\hline \multirow{3}{*}{$\begin{array}{c}\text { CENSO } \\
\text { ESCOLAR } \\
\text { Rede de } \\
\text { Ensino }\end{array}$} & \multirow{2}{*}{\multicolumn{2}{|c|}{1996}} & \multicolumn{6}{|c|}{2005} \\
\hline & & & \multicolumn{2}{|l|}{$\mathrm{EE}$} & \multicolumn{2}{|c|}{ EE (Incluídos) } & \multicolumn{2}{|c|}{ EE (Total) } \\
\hline & $\begin{array}{l}\text { Qtde de } \\
\text { Alunos }\end{array}$ & $\begin{array}{c}\text { Distr. } \\
\%\end{array}$ & $\begin{array}{l}\text { Qtde de } \\
\text { Alunos }\end{array}$ & $\begin{array}{c}\text { Distr. } \\
\%\end{array}$ & $\begin{array}{l}\text { Qtde de } \\
\text { Alunos }\end{array}$ & $\begin{array}{c}\text { Distr. } \\
\%\end{array}$ & $\begin{array}{l}\text { Qtde de } \\
\text { Alunos }\end{array}$ & $\begin{array}{c}\text { Distr. } \\
\%\end{array}$ \\
\hline Brasil & 201.142 & 100,0 & 378.074 & 100,0 & 216.548 & 100,0 & 594.622 & 100,0 \\
\hline Municipal & 29.591 & 14,7 & 68.183 & 18,0 & 139.147 & 64,3 & 207.330 & 34,9 \\
\hline Estadual & 90.688 & 45,1 & 65.206 & 17,2 & 69.850 & 32,2 & 134.156 & 22,6 \\
\hline Federal & 938 & 0,5 & 922 & 0,2 & 110 & 0,1 & 1.032 & 0,2 \\
\hline Particular & 79.925 & 39,7 & 243.763 & 64,5 & 7.44 & 3,4 & 251.204 & 42,2 \\
\hline
\end{tabular}

Fonte: Brasil (2005)

Sobre o número de alunos com NEE atendidos pelos sistemas educacionais, seja ele da rede municipal, estadual, federal e/ou particular, percebemos que apesar do aumento (de 201.142 para 594.622) no número desse alunado atendido por uma dessas redes, no período compreendido entre 1996 e 2005, ainda permanece a existência de uma realidade extremamente excludente, e que a rede de ensino privado, que normalmente são as escolas especiais, apesar da discussão atual sobre o paradigma da inclusão, ainda é a principal responsável pelo aumento no número de atendimento educacional a esse alunado no Brasil.

Portanto, o que os dados demonstram é que apesar das discussões em congressos, nas revistas especializadas da área educacional e no cenário político, ainda há muito por se fazer para aumentar as oportunidades de acesso e permanência do alunado com necessidades educacionais especiais nas escolas do nosso País.

\section{CONTRIBUiÇÕES DA EDUCAÇÃo FÍSICA PARA A INCLUSÃO ESCOLAR DAS PNEE}

Quanto aos caminhos percorridos pela área da Educação Física diante das PNEE, com base nos estudos identificados e selecionados na literatura das áreas de Educação/Educação Especial e Educação Física, verificamos que esta última, enquanto modalidade de ensino, encontra-se 


\section{Revista Soltaa Voz, v. 17, n. 2}

em vantagem em relação às outras disciplinas, especialmente, as escolares, uma vez que a Educação Física Adaptada (EFA) procurou compreender as deficiências e a maneira de adaptá-las, o que a levou ao desenvolvimento.

Podemos dizer que essa expressão EFA surgiu na década de 1950 e foi definido pela American Association for Health, Physical Education, Recreation and Dance (AAHPERD), como sendo um programa diversificado de atividades desenvolvimentistas, jogos e ritmos adequados aos interesses, capacidades e limitações de estudantes com deficiências que não podem se engajar com participação irrestrita, segura e bem sucedida em atividades vigorosas de um programa de Educação Física geral (Pedrinelli, 1994).

Em outros termos, podemos dizer que o programa de Educação Física geral não conseguiu abranger a especificidade das pessoas com deficiência e então, a Educação Física Adaptada veio para suprir essa lacuna existente.

Portanto, a EFA conseguiu perceber os limites e possibilidades dessas pessoas e tem como diretriz trabalhar com as potencialidades dos alunos. Ainda assim, é uma prática segregacionista, pois acontece entre as pessoas com deficiência e, no paradigma da inclusão, estamos falando em lidar com o uno e o diverso em um mesmo contexto.

Sabemos que apenas colocar o conteúdo da atividade física e o desporto adaptado como partes constituintes do conhecimento, a ser trabalhado pelos professores de Educação Física com seus alunos, não asseguraria a inclusão e a participação do aluno com deficiência nas aulas de Educação Física Escolar.

Contudo essas ações poderiam suscitar uma reflexão sobre a temática deficiência, e, principalmente, levar os professores a um repensar acerca da articulação tempo, espaço e conhecimento na Educação Física Escolar, analisando e compreendendo os limites e possibilidades da inclusão desses alunos na escola.

Inserir conhecimentos que abarcassem temáticas da EFA poderia ser um caminho, dentre outros. Mas, é preciso compreensão e clareza sobre qual Educação Física estamos falando e o que queremos para os nossos alunos.

A Educação Física pode ser vista de diferentes maneiras. Por um lado, pode lidar com ideologias "biologicistas", que se preocupam com a estética ou o rendimento físico e técnico do indivíduo e, por outro, pode-se propor a trabalhar enfatizando os aspectos histórico-sociais do indivíduo. Dependendo da forma de conceber a EF, não é difícil legitimar 
a exclusão de alunos de determinadas atividades, sejam eles PNEE, ou não. Já vivenciamos muitas vezes a exclusão disfarçada dos menos hábeis, dos mais gordinhos, dos mais lentos, enfim, daqueles que não se enquadram no padrão preestabelecido.

Não podemos negar que ainda é realidade, em algumas escolas, aulas de Educação Física separadas por turmas, tendo com parâmetros o sexo e o nível de habilidade motora, demonstrando, nitidamente, a bagagem histórica, cultural, social e educativa que nos acompanha e, historicamente, deve ter acompanhado nossos antecessores.

Muitas vezes, esses princípios vêm contribuir fortemente para o processo de exclusão escolar desses alunos, como dissemos, anteriormente. E, excluindo, perdemos a oportunidade de aprender a conviver com o diferente.

Aranha afirma que:

alijando-se o aluno com deficiência da integração social, este perde em desenvolvimento, enquanto a sociedade perde por não ter a oportunidade e a possibilidade de aprender com uma significativa parcela de seus elementos constitutivos, representados pelos "diferentes" segregados. Com isso, todos perdemos consciência, em comportamento e, conseqüentemente, em possibilidade de transformação (Aranha apud Cruz, 1996, p. 12).

Ressaltamos as contribuições do aluno com deficiência para sua própria inserção social, no que se refere à transformação que poderá trazer à Educação Física, se estiver presente, integrado, incluso nesse contexto.

Reconhecemos que existe, ainda, na educação e, conseqüentemente, nas aulas de Educação Física, perspectivas tradicionais de ensino. Desta forma, temos consciência de que ao defendermos a possibilidade de inclusão do aluno com necessidades especiais na Educação Física Escolar, estamos avançando às perspectivas mais progressistas de ensino, tais como: crítico-social, crítico-superadora, emancipatória, entre outras, pois apesar destas, considerarem os mecanismos de exclusão, normalmente, presentes nas aulas de Educação Física, nenhuma delas referem-se e analisam com profundidade sobre a inserção dos alunos com NEE, especialmente, as PD nas aulas dessa disciplina escolar.

Os professores de Educação Física, principalmente aqueles que trabalham com essas perspectivas consideradas avançadas de ensino, devem, pelo menos, suscitar um repensar nos objetivos, métodos, funções sociais, 


\section{RevistaSoltaa Voz, v. 17, n. 2}

tempo, espaço e conhecimento para incluir os alunos com NEE, especialmente, aqueles com deficiência nas aulas de Educação Física Escolar.

A inclusão proporciona uma visão arrojada de escola, de ensino, de educação e de Educação Física. Para tanto, torna-se indispensável a valorização do magistério, o investimento na formação dos professores, assim como melhores condições de trabalho e salários dignos, em face do papel político e social que representam esses profissionais (Carvalho, 1999).

Concordamos com Muñoz Palafox et al. (no prelo) quando afirmam que deve ser feito um esforço político para efetivação dos professores na carreira docente mediante a formalização de contratos que estipulem o pagamento de salários por período integral para que possam dispor de tempo suficiente para participar da construção e monitoramento do projeto político-pedagógico e da proposta curricular das suas escolas, pois estes são alguns dos fatores que têm limitado, seriamente, a possibilidade de que esses mesmos professores organizem sua prática docente para refletir coletivamente e intervir criticamente nas escolas com a finalidade de contribuir para a tão ansiada melhoria do ensino público. Deve-se lembrar aqui, que ao tratar do magistério da Educação Básica, o Plano Nacional de Educação (PNE) é claro ao propor na Meta número dois (2) que trata desse assunto, que seja iniciada, imediatamente, a implantação gradual da jornada de trabalho de tempo integral, quando conveniente, cumprida em um único estabelecimento escolar (Brasil, 2004).

Os mesmos autores acrescentam a isso, o fato de que a situação econômica dos professores de ensino fundamental no País continua precária, pois de acordo com o relatório da Avaliação Técnica do PNE para o período 2000-2003 (Brasil, 2004), a média salarial no Brasil era de R\$ 422,00 (U\$ 192,00) para os professores de ensino infantil, R\$ 461,67 da $1^{a}$ a $4^{a}$ séries (U\$ 200,00) e de $\mathrm{R} \$ 599,85$ de $5^{\mathrm{a}}$ a $8^{\mathrm{a}}$ séries (U\$261,00) no ano de 2001. Além disso, no final de 2003 era notório o fato de que, apesar da necessidade de serem atualizados os Planos de Carreira dos sistemas municipais e estaduais de ensino para melhorar o salário docente, muitos ainda não tinham procedido a sua elaboração e aqueles que o fizeram

não o implementaram nas suas dimensões relativas a progressão horizontal, avaliação de desempenho e estímulo ao aperfeiçoamento docente. Mesmo os salários, que receberam um significativo impacto do FUNDEF em seus momentos iniciais, foram com o tempo desgastados em seu valor, diante das definiçôes de valor mínimo nacional/ano adotadas pelo governo federal (Brasil, 2004, p. 95). 
Precisamos enfrentar os desafios, mas não podemos "abraçar" a inclusão sem considerar as idéias liberais contidas nos discursos, as restriçôes, os pontos fundamentais e determinantes levantados nos estudos e pesquisas, tanto em nível nacional quanto internacional, as especificidades de cada deficiência e do alunado da Educação Especial. E, também não podemos deixar de pensar em como articular o tempo, o espaço e o conhecimento na Educação Física Escolar que contemple não só o aluno com deficiência, mas o princípio da diversidade (singularidade) da diferença na unidade (universalidade).

Abranches defende a idéia que

o convívio social só é possível pela aceitação e pelo respeito à diferença. E a diferença é a marca constitutiva de cada sujeito; é o que nos define e nos torna únicos (Abranches, 2000, p. 38).

É importante mencionar que não se pode esquecer que a Educação Física Escolar é parte constituinte do currículo escolar. Segundo Coletivo de Autores (1992), a Educação Física, como componente curricular, possui as mesmas atribuições que a escola em geral, não podemos ser isentada da responsabilidade que se exige da escola.

Assim, entende-se que na Educação Física Inclusiva precisamos estar envolvidos numa prática sócio-político-pedagógica capaz de materializar em uma nova Educação Física Escolar e novos caminhos a serem percorridos.

\section{Conclusão}

Após a realização desses procedimentos, constatamos que, a partir, das duas grandes Guerras Mundiais, houve avanços na área Educacional, voltada às PNEE, principalmente, com os movimentos de normalização, integração e inclusão.

No entanto, ainda precisamos ter olhar crítico para com as práticas inclusivistas que estão sendo e ainda serão materializadas, pois quando nos referimos à inclusão, não estamos tratando da inclusão de um aluno na escola ou alguns alunos na rede de ensino, mas sim de políticas sociais, especialmente, as educacionais e que estas sejam formuladas e implantadas com a intenção de romper com a lógica excludente que vigora em nossa sociedade hodierna. 


\section{Revista Soltaa Voz, v. 17, n. 2}

Quanto ao papel da Educação Física Escolar, diante do paradigma da inclusão, podemos concluir que na sua especificidade esta disciplina poderá recorrer às produçōes da EFA e superá-las, no intuito, de incluir os alunos com NEE em suas aulas. Além disso, poderá inicialmente orientar o seu trabalho por metodologias que favoreçam a compreensão dos elementos da cultura corporal, o que possibilitará ao professor de Educação Física trabalhar as diferentes dimensões da formação humana (Instrumental, Social e Comunicativa).

A Educação Física Escolar, na unidade com as outras disciplinas escolares (Física, Química, Biologia, Matemática, História, Geografia, Língua Portuguesa, Língua Estrangeira, Sociologia, Filosofia, Educação Artística e outras), precisa repensar a organicidade escolar, rever os objetivos do processo de escolarização, discutir sobre as diferentes dimensões da formação humana, analisar o tempo e o espaço de aprendizagem escolar, e em face, da necessidade de superar os mecanismos de controle e exclusão das diferenças (étnico-raciais, de gênero, de classe social, de compreensão cognitiva, social e afetiva) no âmbito escolar, rever a sua prática sócio-político-pedagógica, no intuito de materializá-la como inclusiva.

Enfim, o paradigma da inclusão e mais precisamente, a inclusão escolar, nos coloca a necessidade de superarmos a atual organicidade da escola brasileira, de forma a redimensionarmos o tempo e o espaço escolar, considerando o estatuto histórico dos alunos e o processo que se dá à construção do conhecimento. Os educadores precisam aproveitar as propostas e experiências bem-sucedidas de inclusão escolar, já implantadas no Brasil e no exterior, especialmente, no tocante às especificidades de cada "deficiência" e aos limites e possibilidades do "alunado" da Educação Especial.

Estas propostas de mudanças da atual organicidade escolar brasileira precisam ser subsidiadas por meio de investimentos na formação profissional, melhores condições de trabalho, salários mais dignos, dito de outra forma, que se valorize o magistério em face do papel político e social que representam esses profissionais, na construção de um outro modelo escolar, que seja capaz de universalizar o acesso e garantir a permanência de todos os alunos nas escolas brasileiras.

\section{REFERÊNCIAS}

ABRANCHES, C. Inclusão no trabalho. In: Abranches, C. et al. Inclusão dá trabalho. Belo Horizonte: Armazém de idéias, 2000. 
ARANHA, M.S.F. Inclusão social e municipalização. In: MANZINI, E.J. (Org.). Educação Especial: temas atuais. Marília: Unesp, 2000. Publicações.

BRASIL. Constituição Federal (1988). Constituição da República Federativa do Brasil. Brasília, DF: Senado Federal, 1988.

Coordenadoria Nacional para Integração da Pessoa Portadora de Deficiência (CORDE). Declaração de Salamanca e Linha de Ação sobre Necessidades Educativas Especiais. Brasília, DF. 1994.

. Ministério da Educação e Cultura. Lei no . 9.394, de 23 de dezembro de 1996. Lei que fixa as diretrizes e bases da educação nacional. Brasília - DF. 1996.

BRASIL. Ministério da Educação e Cultura. Secretaria de Educação Fundamental. Secretaria de Educação Especial. Parâmetros Curriculares Nacionais: Adaptaçōes Curriculares. Brasília: MEC/SEF/SEESP, 1999. 62 p.

. Avaliação Técnica do Plano Nacional de Educação. Brasília: Câmara dos deputados, 2004.

. Ministério da Educação e Cultura. Censo Escolar. Brasília, DF. 2005.

BUENO, J. G. S. A inclusão de alunos deficientes na classe comum do ensino regular. Temas sobre Desenvolvimento. São Paulo, v. 9, n. 54, p. 2127, 2001.

CARMO, A. A. do. Educação Comum e especial: discursos diferentes e uma mesma prática excludente. In: MARQUEZINE, M. C. et al. Perspectivas Multidisciplinares em Educação Especial. Londrina: UEL, 1998. p. 391-398.

Inclusão Escolar: roupa nova em corpo velho. Revista Integração, Brasília: MEC/SEESP, n. 23, p. 43-47, 2001.

CARVAlHO, J. M. Pontos e bordados - escritos de História e Politica. Belo Horizonte: UFMG, 1999.

COLETIVO DE AUTORES. Metodologia do ensino da educação física. São Paulo: Cortez, 1992. (Coleção magistério $2^{\circ}$ grau. Série formação do professor). 


\section{RevistaSoltaa Voz, v. 17, n. 2}

CRUZ, G. de C. Classe especial e regular no contexto da educação física: segregar ou integrar? 1996. 80 f. Dissertação (Mestrado em Educação) - Universidade Estadual do Rio de Janeiro, Rio de Janeiro.

DALBÉRIO, M. C. B. Quem são os alunos egressos da Educação Especial? 2000. 193 f. Dissertação (Mestrado em Educação) - Universidade Federal de Uberlândia, Uberlândia, 2000.

DORÉ, R. et al. A integração escolar: os principais conceitos, os desafios e os fatores de sucesso no secundário. In: MANTOAN, M. T. E. et al. Integração de pessoas com deficiência: contribuições para uma reflexão sobre o tema. São Paulo: Menom/SENAC, 1998. p. 174-183.

FERREIRA, J. R. A nova LDB e as necessidades educativas especiais. Cad. CEDES. [online]. Set. 1998, v. 19, n. 46, p.7-15. Disponível em: <http:// www.scielo.br/scielo>. ISSN 0101-3262. Acesso em: 1 dez. 2003.

FOLHA DE SÃO PAULO. A mancha do analfabetismo. São Paulo, 27 mar. 2001. Folha Trainee (caderno especial, p. 8).

FRIGOTTO, G. O contexto sócio político brasileiro e a educação nas décadas de 70/90. Contexto \& Educação, Universidade de Ijuí, ano 6, n. 24, p.43-57, out./dez. 1991.

KASSAR, M. de C. M. Liberalismo, neoliberalismo e educação especial: algumas implicações. Cad. CEDES. [online]. Set. 1998, v. 19, n. 46, p. 16-28. Disponível em: <http://www.scielo.br/scielo>. ISSN 0101-3262. Acesso em: 1 dez. 2003.

MANTOAN, M. T. E. et al. A integração de pessoas com deficiência: contribuiçõos para uma reflexão sobre o tema. São Paulo: Memnon/SENAC, 1997.

Educação escolar de deficientes mentais: Problemas para a pesquisa e o desenvolvimento. Cadernos Cedes: a nova LDB e as Necessidades Educativas Especiais. Campinas/SP: Unicamp, 1998. p. 93-107, n. 46.

MENDES, E.G. Bases históricas da educação especial no brasil e a perspectiva da educação inclusiva. Mimeo. 2000.

Raizes históricas da educação inclusiva. Mimeo. (s.d). 
MENDES, E. G. Perspectivas para a construção da Escola Inclusiva no Brasil. In: M. Palhares \& S. Marins (Org.). A escola inclusiva. São Carlos: EDUFSCar, 2002. p. 61-85.

MITTLER, P. Inclusão escolar é transformação na sociedade. Revista Presença Pedagógica: Inclusão/exclusão escolar. Belo Horizonte: Dimensão, v. 5, n. 30, p. 5-16, 1999.

MUÑOZ PALAFOX, G. H. et al. Reforma Curricular dos Cursos de Licenciatura em Educação Física: Contribuiçōes dos professores das redes públicas de ensino. No prelo.

PEDRINELLI, V. J. Educação Física Adaptada: conceituação e terminologia. In: PEDRINELLI, V. J. et al. Educação Física e desporto para pessoas portadoras de deficiência. Brasília: MEC/SEDES, 1994. p. 7-10.

SAINT-LAURENT, L. A educação de alunos com necessidades especiais. In: MANTOAN, M. T. E. et al. A integração de pessoas com deficiência: contribuições para uma reflexão sobre o tema. São Paulo: Memnon/SENAC, 1997. p. 67-76.

SASSAKI, R. K. Inclusão: construindo uma sociedade para todos. Rio de Janeiro: WVA, 1997. 176 p.

. Revista Integração. Brasília: MEC/SEESP, n. 20, p. 8-10, 1998.

STAINBACK, S.; STAINBACK, W. Inclusão: um guia para educadores. Porto Alegre: Artes Médicas Sul, 1999.

Recebido em: 7 mar. 2006

Aceito em: 7 nov. 2006 